\title{
The Ethics of Financial Market Making and Its Implications for High-Frequency Trading
}

\author{
Andrea Roncella $^{1}$ (D) Ignacio Ferrero $^{2}$
}

Received: 5 March 2020 / Accepted: 19 July 2021 / Published online: 28 July 2021

(c) The Author(s) 2021

\begin{abstract}
During the last 20 years, the financial sector has undergone an unprecedented transformation due to new regulations and the implementation of several technological advancements. The combination of regulation and technology has brought about new financial processes that have fundamentally changed how financial market making is done. This paper studies the ethics of financial market making and its implications for one of the most controversial financial innovations of modern times, namely high-frequency trading (HFT). We claim that the Aristotelian distinction between natural chrematistics, which is aimed at serving the real economy, and unnatural chrematistics, whose ultimate purpose is wealth accumulation, can be a useful criterion to assess the ethics of financial market making and the goodness of an innovation as HFT, and how it can serve the common good of society. This approach can be defined as 'purpose oriented' or 'purpose fulfillment'.
\end{abstract}

Keywords Market making $\cdot$ High-frequency trading $\cdot$ Aristotle $\cdot$ Virtue ethics $\cdot$ Purpose

\section{Introduction}

For as long as people have been trading stocks there have been intermediaries, or market makers. A market maker is a dealer who conducts a two-sided auction for securities by standing ready to trade on either side of the market for his or her own account when an order arrives (O'Hara and Oldfield 1986). The scope of market making is then to offer liquidity between the buyer and the seller when there is no temporal match in order to maintain an orderly market. An adequate or "good level" of liquidity is necessary for the correct functioning of the market, which in turn allows for economic growth. This "good level" does not mean an exact level of liquidity in mathematical terms, whatever the circumstances: increasing the level of liquidity in normal times or for stocks normally traded is less important than securing liquidity in

Andrea Roncella

andrea.roncella@unisi.it

Ignacio Ferrero

jiferrero@unav.es

1 School of Economics and Management, University of Siena, Siena, Italy

2 School of Economics and Business, University of Navarra, Pamplona, Spain times of stressed markets, or for stocks that are struggling to find a buyer or seller.

Given its relevance, market making has thus been the subject of countless theories within market microstructure, describing how market makers act, what challenges they face, and how they generate profits (O'Hara, 1998).

Notwithstanding their centrality for the functioning of the financial markets, market-makers have been often blamed, specially over the last 20 years. Since 2005 market-making has in fact undergone a deep transformation due to regulation and technological changes which brought new players, institutions and rules of the game (Angel et al. 2015). In particular, high-frequency traders have become the new market makers (Menkveld, 2013).

Yet, popular controversies around high-frequency trading (HFT) suggest that many market participants are dissatisfied with the role of high-frequency traders as market makers (Lewis, 2014). As the stock markets of the world become increasingly electronic, the majority of traders never even see the floor of an exchange, and mostly "they feel no commitment to maintaining an orderly market" (Shiller, 2013).

As summarized by Shiller (2013): "in the current environment the greatest hostility is often reserved for the traders [among whom he mentions market-makers], since they usually do not present themselves as helping society in any direct way. They are just buying and selling to try to make 
money for themselves". A normative theory of market making is therefore particularly required in the age of HFT. Guidance is thus needed about how market makers should act, and such guidance could help evaluate and potentially redirect the activities of high-frequency traders as market makers.

This paper focuses therefore on the transformation of market making, mainly because of the rapid adoption of HFT, which has come to account for more than half of all US equity trading (Gerig, 2015). In our assessment of the aim of market making activity, we will provide an ethical evaluation to inform the debate about HFT, asking to what extent it contributes to the fulfillment of market making's purpose.

In doing so, this paper aims to take up the broader challenge laid down by Zingales. In his 2014 presidential address to the American Finance Association, Zingales encouraged financial scholars to assess the contribution of finance to society by overcoming the sole criterion of efficiency (Zingales 2014). He also draws a distinction between good and bad finance. The former is "competitive, democratic, inclusive and it needs public support to operate"; the latter is "noncompetitive, plutocratic, 'clubbish' and lives off political protection" (Zingales 2014, p. 1338).

Since HFT's disruption of market making, several business ethicists and philosophers tried to provide a normative assessment for it, but a final word is far too be achieved. Along this line, we develop a normative theory of market making by drawing on Aristotle. Specifically, the key insight we take from the Greek philosopher is his distinction between natural and unnatural chrematistics.

Aristotle was particularly concerned with the nature of the supreme good of man, which he identifies as 'happiness' or flourishing. Given the nature of human beings as 'political animals', flourishing can only be achieved within political communities, which is why Politics was deemed the most important science. To live a flourished life, human beings need both external or material goods, and internal or goods of the soul. Economy takes care of the former, and Ethics of the latter. The Stagira claims that a necessary condition to attain happiness is to pursue material goods only as a means to obtain internal ones. In his analysis of Athenian society, Aristotle makes an important distinction between the economy ('oikonomia') or the 'economy proper', defined as the use of wealth or wealth management, and the 'chrematistics', which refers to wealth acquisition or production. He also differentiates between natural and unnatural wealth production, depending on whether it fulfills its purpose and observes its limit (Aristotle, 1990, p. 1253b). Inasmuch as chrematistics provides the adequate amount of material goods useful for life, it is proper and natural, helps to achieve human flourishing and can be considered good finance. On the contrary, if it is exclusively focused on accruing wealth, chrematistics becomes an unnatural, transformation of the means into an end, which obstruct the happiness of human beings. In this case, it is deemed a bad financial practice.

Following other authors who have previously applied Aristotle's notion of natural and unnatural chrematistics to finance in general (Ferrero \& Sison, 2017); to management (Dierksmeier \& Pirson, 2009); and to usury (Schlag, 2017), we will use this framework to assess if financial market making is benefiting society, and how this activity can still contribute to the common good of society.

The rest of the paper is structured as follows: Sect. 2 presents an overview of how market making benefits the financial system and the broader economy; it further analyses the transformation of the market making activity due to regulation and technological development that brought HFT as an innovation to the market. Section 3 explores Aristotelian ethics and how its principles help in the assessment of whether and how market making contributes to the common good. Section 4 analyzes HFT's contribution to the fulfillment of the purpose of market making and hence, its implications for society. Last, the paper summarizes the main arguments, draws conclusions and makes recommendations about future research.

\section{The Role of Market Making in the Financial System, and the Emergence of HFT}

Historically market makers matched buyers and sellers. They posted two prices for every stock in which they made a market: the price at which they were willing to buy the stock-i.e. the bid price-and the price at which they were willing to sell the stock-i.e. the ask price. When a customer arrived and wanted to make a trade a these prices, the market maker would honor the posted prices and make the trade even when they did not have another customer willing to take the other side of the trade. In this way, market makers provided liquidity by ensuring that market participants always had somebody to trade with.

Liquidity of an asset refers to the ability of buyers and sellers of securities to transact an asset in a timely manner at a fair price. An improvement of the liquidity - a high level of market liquidity-implies a better possibility to exchange shares in the secondary market and hence to reduce the cost of capital for firms and to promote economic growth (Elliott, 2015).

Conversely, a lower level of market liquidity reduces the efficiency with which funds are intermediated from savers to borrowers and can potentially inhibit economic growth. A low market liquidity is also likely to be fragile and prone to evaporation in response to shocks. When liquidity drops sharply, prices become less informative and less aligned with fundamentals, and tend to overreact, increasing volatility. In extreme conditions, markets can freeze altogether and 
lead to systemic repercussions (International Monetary Fund 2015). The role of the market makers is particularly relevant during times when markets are uneasy and market activity characterizes only by buying or selling securities. Market makers then typically adopt a position contrary to the flow of the market: they sell when others buy and buy when others sell. This implies that market makers have enough economic resources to buy securities from investors who want to sell while also holding an inventory of securities for those investors who want to buy. Nowadays, to alleviate these problems, in some markets such as the NYSE (New York Stock Exchange), designated market makers have the obligation to provide liquidity in return for certain advantages. As incentive, market makers earn a commission based on the bid/ask spread which has an underlying profit rationale that factors in a twofold risk that market makers are exposed to, namely (1) holding assets that can suffer a (dramatic) change in price and; (2) trading with someone better informed about the true price of the assets. Hence, the bid-ask spread serves as an insurance for market makers against risk from depreciating and mispricing (Haldane, 2012).

The intermediary position held by market makers give them a privileged view of incoming orders, with the threat that these may generate unfair profits to the detriment of the investors. The most widespread risk is that of front-running, that is profiting by placing one's own orders ahead of a large order based on information of that impending order. Front-running is similar to insider trading in that it harms the functioning of the market not only because it jeopardizes the trust necessary for trading, but also because it is a disincentive for informed investors to invest in fundamentals research (Melé, 2019, p. 137). Against this and others risks, regulators have promulgated several norms that aim to curb the kinds of actions that market makers were allowed to do (negative obligations), while at the same time, strive to ensure their positive role where market makers provide a continuous liquidity even in periods of stressed markets (positive obligations). Far from considering the traditional activity of market makers as devoid of distortions and misleading behaviors, the existence of a regulation guaranteed at least the possibility to call for legal procedures when they did not fulfill their function (Abolafia, 2001).

Financial markets have been radically transformed over the last 20 years. O'Hara (2015) argues that two main drivers brought about this change are regulation and technology. This is more evident on equity markets in the US and EU, where, starting in the ' $90 \mathrm{~s}$, a number of reforms have been undertaken that eventually led to Regulation ATS (Alternative Trading System) and Regulation NMS (National Market System) in the US and MiFID I and II (Markets in Financial Instruments Directives) in EU. Even though each of them has its own specificity, the design and implementation of these norms had the explicit aim of fostering competition and indirectly, the efficiency of capital markets through the fragmentation of the stock exchanges. Consequently, the number of venues multiplied, with trading dispersed across a variety of exchanges and markets (O'Hara 2015). The new regulatory framework made possible the substitution of old equilibria with new entrants, who are better organized and more able to take advantage of the opportunities.

It is in this new context that technology, as one of the primary drivers of change, has demonstrated its potential. According to O'Hara, in a fragmented market the more informed investors are the quickest and not the smartest anymore. On the surface, this is nothing new with respect to the typical dynamism of a capitalist economy, and facilitated partially by the state, as it seeks to substitute roles and practices. It is precisely in this new environment that highfrequency trading (HFT) emerged (O'Hara, 2015).

HFT could be defined as a subset of algorithmic trading ${ }^{1}$ whose activities resemble a technological version of activities long undertaken in the market, such as market making and arbitrage, among others.

According to the definition provided by the Securities and Exchange Commission (SEC), high-frequency traders are "professional traders acting in a proprietary capacity that engage in strategies that generate a large number of trades on daily basis" (SEC, 2010, p. 45). Even though these traders can have different kinds of strategies, the SEC identifies some common characteristics, such as: (1) the use of highspeed and sophisticated computer programs for generating, routing and executing orders; (2) co-location services and individual data feeds ${ }^{2}$ to minimize network and latency; (3) short time-frames for establishing and liquidating positions; (4) the submission of numerous orders that are cancelled shortly after submission; (5) the maintenance of a flat position at the end of the day (SEC, 2010, p. 45).

The changes that lead to technology-based and fragmented markets allowed HFT firms to take over market making activity, replacing the old players, and becoming the 'new' market makers (Menkveld, 2013, p. 716; O'Hara, 2016, p. 259; Brogaard et al., 2014, p. 2267; Carrion, 2013, p. 681). Given its new, dominant role in the US equity market, this innovation has drawn the attention of a large number of observers and sparked a public debate on its effects on the market (Marti \& Scherer, 2016). In particular:

\footnotetext{
1 Algorithmic trading allows for trading strategies to be programmed into an algorithm, which is simply a self-contained step-by-step set of operations to be performed (O'Hara 2016).

${ }^{2}$ Data is released directly to clients at precisely the same time that it is sent to the Securities Information Processor (SIP); given the inherent delays in transmission and processing by the SIP, a direct data feed is therefore a few milliseconds ahead of the SIP. Enriched data feeds provide a greater breadth of information than is sent to the SIP (McNamara 2016, p. 110).
} 
(i) Financial economists are concerned with understanding HFT's effects on market efficiency. Hendershott et al. (2011) found that HFT - as an algorithmic trading's subset-improves the liquidity for the shares of firms with large market capitalization by reducing the transaction costs, that is, the bid/ask spread. Along a similar way, Brogaard et al. (2014) found that HFT improves price discovery. However, the CFTC-SEC commission (2010b) and Kirilenko et al. (2017) underlined the role of HFT in exacerbating market volatility when exogenous causes are involved as in the case of the Flash Crash, when in the space of just 36 min the Dow Jones Index lost almost a tenth of its value, only to rebound soon afterwards as if nothing had happened.

(ii) Regulators are concerned about HFT's consequences in terms of stability. Reports from the Deutsche Bundesbank (2016), Bank of England (Anderson et al., 2015), Tokyo Stock Exchange (Jain et al., 2016) agree that the behavior of HFTs in stressed conditions is uncertain. This is due to the risk that they might exit financial markets when previous shortterm empirical relationships start to break down, reducing the overall liquidity. This decrease might exacerbate price spirals by selling into a falling market, explicitly undermining liquidity. In the European Union, these concerns have fostered regulatory policies, such as MiFID II, aimed at reducing the negative externalities attributed to HFT firms (Busch 2016).

(iii) Business ethicists and management scholars raise questions about HFT and justice, both in terms of single strategies pursued by high-frequency traders as well as of the innovation itself (Marti \& Scherer, 2016).

The harsh criticisms levelled at HFT as set out in popular books such as Flash Boys (Lewis, 2014) and Broken Markets (Arnuk \& Saluzzi, 2012), raised the suspicion that financial markets were 'rigged' at the expense of institutional and retail investors and in favor of HFT firms. These books claim that the complexity of contemporary stock markets comes from its automation, fragmentation and other complications, serving the interests of financial intermediaries (HFT firms among them) rather than those whom the market should attend to such as investors and corporations. Following these publications, ethics scholars have analyzed the possible ethical inconsistencies of HFT.

Some business ethicists state that although some trading strategies such as spoofing (consisting of a sequence of limit-orders that are added and then canceled with the intention that other algorithmic traders would interpret the data incorrectly or not quickly enough), and quote stuffing are deceptive $^{3}$ and are designed with the explicit aim to mislead investors, HFT itself is not unjust (Angel \& McCabe, 2013; O'Hara, 2016). Their analysis of different accounts of the idea of justice sheds some light on the use of controversial HFT services, such as co-location. This high-payment service allows traders to place their computers next to the exchanges' data centers in order to gain time advantage to the detriment of other investors deprived of this service (Rogow, 2012). While this service leads to increased and significant revenues for both HFT firms and exchanges, it poses an issue of fairness. However, Angel and McCabe do not find any incongruence neither from a procedural account of justice-this kind of services is available to all those investors who want to pay for them-nor from a distributive point of view. They state that, "our societies tolerate such inequality in a market economy, because market incentives are a tremendous incentive for efficient production of good and services" (2013, p. 594). Even when analyzing HFT colocation services from the Rawlsian Original Position, the authors believe that such services could be justified given the better quality, both in terms of liquidity and price discovery, which eventually benefits all the market participants (2013, p. 592). However, their analysis is rooted in a preference for the efficiency argument over that of justice.

O'Hara (2016) reaches a similar conclusion. She questions the extent to which the existence of a 'two speed' market can actually be fair. In other words, at what point does the advantages that the HFTs firms have such as ultrafast computers, colocation, and proprietary data feeds, become unfair? O'Hara explains why perfect coordination in the market, where information reaches all the traders at the same time, is unlikely to be attained "and so neither is perfect fairness” (2016, p. 145). According to O'Hara, a less idealistic approach to justice should take into account the different needs of the various kinds of traders, respecting the principle of 'reasonable discrimination'. However, the author acknowledges that "putting your needs above those of others is unethical" (2016, p. 146), and therefore, it is not as straightforward as it might seem that a two-tier market may be justified by the differences among the traders. On the contrary, some ethics scholars do not consider spoofing and quote stuffing unethical, and suggest a more positive interpretation. For example, Cooper et al. (2016) argue that as in the game of poker, these forms of misleading behavior should also be accepted in the financial markets. The authors claim that these practices are part of an 'evolutionary process' through which only the best firms survive, eventually leading to a general benefit for society. Furthermore, they

\footnotetext{
3 These strategies and algorithms have been banished by market regulation (e.g. EU Market Abuse Regulation or Sect. 747 of Dodd Frank Act).
} 
state that effectiveness should be the aim of markets, and therefore the regulatory over-focus on the ethics of intent misses the point (see also Cooper et al., 2020).

Most business ethicists assign a primary role to the market efficiency's criterion when they assess HFT's contribution to society. However, some reject an exclusively utilitarian framework focused on the efficiency-stability tradeoff that conforms to a cost-benefit analysis. McNamara is not convinced by the efficiency criterion for two main reasons: (1) it admits the sacrifice of certain individuals for the greater good (greater efficiency) of the financial markets; (2) the high number of trading venues, market participants, and regulations augments the size of the market so that it becomes impossible to make definitive statements on the correlation of causes and effects (2016, p. 125). McNamara proposes a different approach based on Boatright (2013), which adds the principle of reciprocity to the existing criteria of economic costs and benefits, thereby reflecting a fundamentally deontological ethical stance. He argues that this principle is particularly useful as ex ante regulatory guides, and that it can constitute a basis, where a cost-benefit analysis in isolation fails to safeguard the interests of all the market actors (McNamara, 2016, p. 151).

Sandel provides an interesting reflection about the primacy of efficiency. He states that, "efficiency only matters insofar as it makes society better off. But what counts as better off?" (2013, p. 122). The problem lies in establishing this criterion. For instance, an innovation can make the economy, or a market, more efficient, but this can happen at the cost of a negative externality, i.e. corruption or degradation of social practices and institutions. Sandel presents several examples (2012) that show how market mechanisms can eventually lead to this corruption or degradation. Although Sandel's reflection is particularly concerned with how market mentality has invaded societal spheres resulting in a shift from a 'market economy' to a 'market society', we believe that the degradation of institutions can involve the market itself, when it is 'dis-embedded' from the rest of society. Following this line of thought, a financial innovation as HFT is good insofar it contributes to the fulfillment of the purpose of an institution such as the market, and only once this has been achieved, we could consider the efficiency argument.

Miller (2017) develops a similar normative theory, defined as a 'teleological account of institution'. He raises three questions when judging a financial institution, namely: (1) What ought to be the principal institutional purpose of the various financial markets? (2) Is this market structured to adequately realize its institutional purpose? (3) What role ought the financial market to play in the larger economic order? (Miller, 2017, p. 9). Accordingly, he found that an equity market characterized by its shorttermism and dominated by HFT is incoherent with its purpose, that is: "to provide an adequate and sustainable supply of financial capital to productive firms at a reasonable cost" (Miller, 2017, p. 23). Unfortunately, he does not delve into the details to explain why this is the case. Furthermore, financial markets do more than just allocate capital. They provide risk management tools to allow market participants to reduce their risk through diversification or hedging; offer investment opportunities that reward savers for deferring consumption; and makes available liquidity for investors who need to exit, which makes it easier for investors to invest in the first place. In addition, market prices provide useful information to policy makers about the impact that policies might have.

In this brief review of the main literature on the ethics of HFT, we discussed the major approaches to normative ethics. The efficiency-stability tradeoff is typical of a utilitarian cost-benefit analysis and is not conclusive. McNamara's approach of the principle of reciprocity calls for the return to a deontological framework to deal with the regulatory issue of HFT in particular. The paper by Marti and Scherer (2016) also supports this approach, albeit from a different perspective.

In this paper, we continue with Miller's starting point, adopting a teleological approach to financial institutions, but moving from a deontological perspective to a virtue ethics one. We will specifically apply the Aristotelian insights on economics and finance to financial market making and HFT.

Together with deontology and utilitarianism, virtue ethics is one of three major approaches in normative ethics (Ferrero \& Sison, 2014). "Like deontology, virtue ethics upholds universal principles, but unlike deontology, it considers the intentions of agents and the circumstances within which actions take place. Similarly, like utilitarianism, virtue ethics takes results or outcomes into account, but unlike utilitarianism, it maintains that certain actions are prohibited without exception. Therefore, decision making in accordance with virtue ethics requires an analysis of the object, circumstances and consequences of an action as well as the agent's intentions" (Ferrero \& Sison, 2017). In this approach, virtue is defined as a "freely acquired habitual disposition that enables one to perceive, experience emotions, deliberate, decide, and act in a proper way; it is also the controlling factor for eudaimonia (human flourishing)" (Ferrero \& Sison, 2014, p. 386). Such a definition of virtue and its relation to flourishing has its roots in the Aristotelian corpus, particularly in the Nicomachean Ethics.

Our analysis will consider the Aristotelian distinction between natural and unnatural chrematistics, whose discernment are first explained followed by a discussion on whether HFT contributes to pursuing the market making's purpose. Given that Aristotelian ethics is a form of virtue ethics, our concern is also the moral consequences for the financial agents who perform or embed strategies for high-frequency trading in software that control the computer. 
In this sense, we combine a double dimension which is both systemic and individual, thereby making explicit the necessary synthesis between institutions and individuals that make organizations virtuous, as underlined by Moore and Beadle (2006) and Sison (2003), among others.

Regarding the systemic dimension, our paper refers to the difference between natural and unnatural chrematistics. This distinction connects with several insights on the 'purpose' of companies: a topic which is attracting increasing attention in the business literature. We think the distinction between means and ends (also identified by scholars such as Edmans, 2020), can find a solid theoretical foundation precisely in the Aristotelian tradition. In this sense, this paper also involves an element of originality, providing a philosophical foundation for the research on the purpose of corporations. Once this systemic consideration has been established, we delve into the individual dimension, through the analysis of virtues, intentions, and circumstances.

\section{The Aristotelian Approach to Finance}

After a long absence from the public discourse, some contemporary moral philosophers (Anscombe, 1958; MacIntyre, 1984) have revived Aristotelian teachings on ethics. Similarly, business ethics scholars started to apply these Aristotelian insights to the business framework (Solomon, 1992; Hartman, 1996; Moore, 2008; McCloskey 2006; Ferrero \& Sison, 2014; Sison et al., 2017). However, Aristotle's distinction between oikonomia and chrematistics, and between natural and unnatural chrematistics, have not drawn the same attention, with some exceptions such as Dierskmeier and Pirson (2009), Crespo (2014), Meikle (1994), and Ferrero and Sison (2017). We, however, think that this Aristotelian distinction provides an adequate framework not only "to think through contemporary dilemmas in the field of business ethics" (Dierskmeier and Pirson 2009, p. 424), but also to establish a criterion to primarily judge the purpose of a financial practice and whether this aim is sustained throughout the evolution and transformation of these practices.

As we mentioned above, Aristotle was particularly concerned with investigating the nature of the supreme good of man-in other words, happiness (Aristotle, 1985, pp. $1094 \mathrm{a}-\mathrm{b})$, and he noted the positive role played by the economy in the pursuit thereof. Happiness, or flourishing, depends on both material (external) and non-material (internal) goods, with the former contingent on achieving the latter (Aristotle, 1990, p. 1323b). Within the economy, or oikonomia, which is the discipline associated with the material goods, Aristotle distinguishes two activities: 'economy proper', which consists of wealth use and enjoyment, and chrematistics which refers to wealth acquisition or production (Ferrero \& Sison, 2017, p. 1155). In its function to provide those "things necessary to life, and useful for the community", chrematistics is secondary to oikonomia (Aristotle, 1990, pp. 1256b, 30), which is the end to which chrematistics should tend.

However, Aristotle distinguishes between natural chrematistics whose purpose is to serve the oikonomia and whose limits are suggested by the virtues; and unnatural chrematistics whose sole purpose is accumulation (Aristotle, 1990, pp. $1257 \mathrm{~b}, 35-40)$. The former provides a service to economy and participates in the achievement of those external goods on which the flourishing of human beings partially depends. Nevertheless, "when the provision of material goods becomes an end in itself, without any other purpose than to have more and more, the chrematistics becomes unnatural, and it represents a threat to happiness" (Ferrero et al., 2020, p. 8). To illustrate this, Aristotle provides the example of shoes: natural chrematistics requires the use of shoes as footwear, while the use of shoes as objects of barter would be improper or non-natural (Aristotle, 1990, p. 1257a).

Aristotle's conception of chrematistics is disputed. Plato, for example, offers a different view on chrematistics: while he agrees with Aristotle that the virtue of an art is the perfection of this art, he deals with chrematistics as an art by itself. Therefore, a shoemaker is a good shoemaker if he brings this art to perfection and makes perfect shoes. On the other hand, he has to sell his shoes and hence he has to be a good merchant too (Plato, 2007, pp. 346a-347a; 1984, p. 478b). However, Aristotle draws a more specific and consistent distinction, whereby he says that a shoemaker perverts the art of shoemaking if his aim is not to make good shoes but mainly to make money with them. The more his trade is focused on money-making, the less perfect he is as shoemaker (Aristotle, 1258a 7-14). For Aristotle, identifying the purpose of something is related to the nature of those things.

In their work on how finance can be virtuous, Ferrero and Sison (2017, p. 1155) explicitly place finance in the 'realm of chrematistics", "inasmuch as finance is an activity that consists in providing money, capital or credit for production or consumption of material goods". Therefore, finance cannot be an end in itself; it has to be purpose-oriented. This association has always been useful to center the debate on concrete issues related to finance. For example, thirteenth century Scholastics used this definition to assess and often condemn practices such as usury (Schlag, 2017). According to these scholars-Thomas Aquinas in particular-money should not produce money but is meant to be a means of exchange for useful goods. In this sense "there is no need for more money than the value of the goods that are available for purchase" (Schlag, 2017, p. 34). In contrast, in the socalled 'chrematistics cycle' ${ }^{4}$ money is exchanged for goods

\footnotetext{
${ }^{4}$ The Scholastics distinguished between the 'economic cycle' where the goods are exchanged for other goods with the help of money (Goods-Money-Goods), and the 'chrematistics cycle' which is the
} 
in order to acquire more money. In this endless cycle, money becomes the aim.

More recently, Dierksmeier and Pirson (2009, p. 417) argue that "the conceptions of chrematistics and oikonomia provide a basis to discuss the relationship between business and society and to draw important conclusions for business management". Along this line, Ferrero and Sison (2017) discuss how to qualify finance as natural chrematistics: the agents of this activity must serve its purpose and observe its limits. These two elements are essential to assess if finance effectively contributes to the common good of society, and whether it is a good activity that participates in the flourishing of human beings.

The debate around the purpose of corporations is becoming extremely important nowadays, as witnessed by consortiums such as "The Future of Corporation" lead by the British Academy, or official statements such as that of the Business Roundtable in 2019. All these initiatives aim to inject purpose into the heart of business. Among the different possible meanings of 'purpose' applied to the business environment (Hsieh et al., 2018), we agree with Edmans (2020, p. 192) for whom: "Purpose is why an enterprise exists - who it serves, its reason for being and the role it plays in the world". It is the answer to the question "how is the world a better place by your company being here?" Purpose is the particular way in which an enterprise serves society.

The Aristotelian framework matches purpose with human flourishing, given that "finance can only be 'virtuous' insofar as money and financial resources are used to acquire, produce or purchase other goods necessary for flourishing, but not an indefinite amount of money" (Ferrero \& Sison, 2017, p. 1155). The purpose, then, "should be to provide material resources as a means to achieve non-material goods such as virtues", which help human beings to live a flourished life or to attain happiness (Ferrero et al., 2020, p. 8).

Moreover, the formula "goods necessary for flourishing" refers to goods and services that are really useful, not simply because they satisfy consumer preferences, but because they safeguard and promote the true human good and contributes in some way to the common good of society. This common good is understood as the sum of those conditions of social life, which allow social groups and their individual members to achieve their own flourishing.

Therefore, a purpose aimed at the common good is the first useful principle to draw a difference-from an Aristotelian perspective-between a proper and an improper finance.

Another principle we can deduct from the Aristotelian scheme, is the intention with which the agents pursue or

\section{Footnote 4 (continued)}

reversal (Money-Goods-Money) (Schlag 2017). This distinction was also drawn by Karl Marx (2004) strive to achieve the purpose of the organization. Moreover, the intentionality is closely related to the limit dimension in the provision of these material goods.

In agreement with Monge and Hsieh (2020), we rely on what they call an Anscombian-Aristotelian approach, according to which "intention is described by the answers to the question "Why are you X-ing?" where it is true that the agent is X-ing and there is an answer to the question "Why?" within the relevant range. The relevant range is defined by answers that provide the chain of means-end reasoning the agent considers being relevant to the actions she undertakes. Thus, intentions are revealed in the explanations an agent gives for acting in a given way" (2020, p. 368).

When we speak about limits in the provision of material goods, we mean human beings only need a finite amount of money to satisfy their physical or bodily needs and attain flourishing. In this sense, chrematistics becomes unnatural and vicious activity, because of the agent's intentions or motives which sees them surpass a reasonable limit and are "overcome by an inordinate desire for wealth or greed, accumulating money for itself" (Sison et al. 2019, p. 996). Importantly, this ideal limit is set by moderation and practical wisdom, since the agent has to judge every particular situation, considering the real intentions, the relevant circumstances, and the expected consequences of each decision. It is, in the end, a "subjective standard". Therefore, practical wisdom plays an essential role in establishing the right amount of financial resources a society needs to serve the real economy.

The Aristotelian notion of virtue is not indifferent to the agent's intentions. This is an important difference between how classical liberalism and Aristotelian virtue ethics understand the achievement of the common good: an unintended externality for the former and an intentional outcome for the latter. The promotion of the common good is not accidental nor is it a mere byproduct of seeking one's self-interest. It rather entails a deliberate effort. This might have two interpretations: (1) a weak interpretation would require to structure the institutional framework in such a way that the agents should be encouraged or nudged to pursue the purpose of their activity, acknowledging that not all of them would do so, opening the door to free-riders (Thaler \& Sunstein, 2003); (2) a more exigent interpretation would demand that-even in absence of an appropriate institutional framework-all the agents eager to live a virtuous life should take into account the intention in their actions.

Summarizing, we identify two principles to assess whether a financial activity is natural (proper) or unnatural (improper) chrematistics (finance): (a) a defined purpose oriented to contributing to the true human good and the common good of society; and (b) a deliberate intention in decisions. 


\section{An Ethical Assessment of the HFT Market Making}

This section explores the purpose of market making (as identified in Sect. 2 of this article) through the analysis of the HFT market makers, and uses the key principles drawn from Aristotelian ethics to assess whether they contribute to the common good. Overall, the Aristotelian assessment we offer may be extended to the analysis of other financial practices and players.

Importantly, our analysis does not concern the market making activity performed by the designated market makers, given that these firms still have some obligations. Moreover, our analysis is not concerned with others typical activities such as arbitrage, nor with a specific trading technique, such as spoofing, nor a particular service, such as the colocation; instead, we are interested in understanding a general market making strategy that HFT firms have pursued. In order to do that, it is key to stress some features of the HFT market makers.

First, HFT market making firms are usually proprietary firms that trade with their own resources and that do not consider investors as their clients but rather as competitors. As a result, they are free to choose and follow different strategies that are convenient and appropriate at the time. As such, HFT market makers are 'ordinary investors' that provide a service of market making, without being contractually mandated by an exchange to do that.

The fragile bargain in the form of a contract that the 'old' market makers pursued (with the exception of NASDAQ and OTC markets) in order to gain an advantage in return for some obligations that they more or less fulfilled, has been entirely transformed by HFTs' entrance. This structural positional advantage of the 'new' market makers still persists, even though it is not assured by a contract but rather by the possibility of exploiting a number of services such as co-location and data feeds, and that de facto enable them to access information and orders of other investors faster than other players. In return for this structural advantage (for which they pay high fees), HFT market making firms in contrast with the old market makers, do not have any positive and/or negative obligations. The greater freedom of HFT market makers, allow them to (1) operate the highest number of trades in as short time as possible; (2) to maintain a very low inventory in order to close the day with a flat position.

HFT's advocates argue correctly that the bid/ask spread which substantially declined as a direct consequence of HFT, signaled a benefit for investors. It is evident however that the bid/ask spread collapsed because its raison d'être disappeared since HFTs do not need a guarantee against price movements given the fact that their holding positions are very short. Nonetheless, some considerations around the relevance of HFT market making services and aims are important and do not always fit the efficiency argument.

We refer in particular to the issue that concerns the type of liquidity that the HFT provides. As noted before, a deeper market liquidity means an increased facility to sell one's investment since an eventual investor would be more predisposed to buy leading to an overall decrease in the cost of capital. Liquidity becomes more relevant when selling a security is effectively more difficult.

In this regard, the role of market makers is a determining factor since in a friction-less market, these market makers would be redundant, as buyers could meet sellers on any occasion. Advocates of HFT claim that the innovation has increased the level of liquidity (Hendershott et al., 2011; Biais 2016) but this only holds true under normal market conditions and for those shares commonly exchanged without any difficulties. In other words, the positive effects found for the 'blue chips' do not hold true for small and medium firms that more than their larger counterparts, need capital markets to raise funds (Hendershott et al., 2011, p. 31; Kirilenko et al., 2017). Furthermore, when analyzing stressed market periods, the arguments in favor of HFT are further up for scrutiny. It is evident that less liquidity corresponds to uneasy markets, but the 'great sin' of high-frequency traders as market makers comes under a period of market stress, when these traders increase the volatility or, simply stop providing liquidity, which is what contributed to the 'Flash Crash'. ${ }^{5}$ Analyzing this case, the CFTC-SEC commission (2010b) underlined the role of HFT in exacerbating market volatility when exogenous causes are involved. The reason for this effect depends on the strategy implemented by HFTs in their role as market makers (Kirilenko et al., 2017). While the 'old' market makers had a positive obligation to provide a continuous liquidity in order to contribute to 'fair and orderly markets', in the high-frequency era such obligation disappeared (with the exception of the NYSE). This fact increases the risk of instability due to a rapid liquidity withdrawal during periods of stressed markets and

\footnotetext{
${ }^{5}$ On the contrary, Biais (2016) shows that even under stressed markets, proprietary traders (and HFTs among them) continue to provide liquidity. However, some comments on his paper leave doubts about this conclusion (comments by Fraga in Biais 2016, p. 26). Similarly, Blocher et al., (2016, p. 7) show that "any phantom-ness in the liquidity [provided by the HFTs] is highly transient and infrequent". We don't disagree with this conclusion but we claim that still there is a problem of relevance with the liquidity provided by HFTs. As with Hendershott (2011) the fact that under normal circumstances HFTs improve liquidity do not mean that is true even under nervous markets. This is the situation we are interested more into because the need for liquidity is greater. In this case, the results of Kirilenko et al. (2017) still hold and therefore also our critique. For this reason, even Blocher et al., (2016, p. 7) claim: "phantom liquidity can really be a problem only if those who cannot get good execution find the price moving against them when they try to trade".
} 
thereby distorting the scope of the market makers. These situations are further exacerbated if the HFT algorithms are programmed to shut down when trading conditions worsen and the possibility of profit-making is reduced.

The fact that HFT liquidity may disappear when it is most needed (also called 'ghost liquidity') brings into question the relevance of HFT for society given the significant costs that such an innovation involves (Stiglitz, 2014). This conclusion has also been reached by Tirole, when he criticizes the considerable sums spent by financial institutions on computing and communications infrastructure so they can execute orders a fraction of a second faster than their competitors (2017). According to Tirole: "It is not obvious what social gain this speed of execution produces. Many people are now calling for a waiting period, so that buy and sell orders are executed only after a slight and uncertain delay. This will put an end to this high-frequency arms race, which is a zerosum game. At the outset, the game is a zero-sum game, the profits made by some being compensated by the losses of others; but it becomes a negative- sum game when we take into account the costs of investment in software, fiber optics, and colocation" (Tirole, 2017).

It is not our intention to sketch a catastrophic situation when comparing HFT with what some consider the "golden age" of the "old' market makers or of the designated market makers. In fact, we know the "golden age" was not "that" golden throughout, as the market crash in 1987 demonstrates. However, we do argue that even though under normal circumstances HFT can lead to more efficient markets, it does not change the fact that the activity of HFT firms should be understood within an unnatural chrematistics cycle, whose aim is not to serve the real economy but rather to accrue profits.

The unnatural chrematistics is acknowledgeable according to the two Aristotelian principles highlighted in the previous section, and now applied to this concrete situation:

(1) The purpose of the HFT no longer seems to be that of a normal market making activity aimed at providing liquidity to the markets, but rather to make profits through the liquidity provision service. This inversion of means and ends corrupts the purpose of market making and points out Aristotle's warning: when the provision of material goods becomes an end in itself, without any other purpose than to have more and more, the chrematistics becomes unnatural, and it represents a threat to happiness.

This first consideration draws on the systemic dimension of the Aristotelian approach adopted in this paper. It concerns the fact that the action of HFTs as market makers is no longer institutionally aimed at achieving the original purpose of this necessary financial activity. To deem the old contractual obligations superfluous to enforce the purpose of the market-making activity, echoes the principle of liberalism according to which the achievement of the common good is not the result of a deliberate will but rather, the consequence of free forces that intervene in a free market. The behavior of HFTs in times of stressed markets has shown that this is not the case and that it is necessary, indeed, that there may be institutions that promote the common good and its pursuit. At a systemic level, therefore, the Aristotelian approach allows us to identify whether the goal towards which a given action is directed contributes to the common good or not.

(2) If we cannot judge the intention of a HFT firm, we can still reiterate that, notwithstanding the case of designated market makers, the institutional framework within which HFT takes place is not designed for the promotion of the common good but rather to guarantee extensive margins of freedom to high-frequency traders. Regarding the use of this freedom, we claim that in normal times, high-frequency traders seem utilize this freedom well, but that in periods of greater market stress, they lack the virtue needed to stay in the markets and sustain its liquidity. In this context, the need for virtuous market makers emerges; in other words, market makers who-aware of the purpose of their activity-use the necessary means to obtain it. At the individual level, some virtues seem particularly relevant in our case. For example, it takes courage to continue providing bid and offer quotes even when it might be easier or more profitable to implement an exit strategy. Similarly, honesty and justice are at play when all clients are treated equally without taking advantage of the information they provide. Likewise, temperance and self-control are equally important in deciding the level of the inventory, according to the nature of the institution. Living out these virtues throughout different times and circumstances requires that the decision-maker exercises practical wisdom. This intellectual virtue suggests the right thing to do in light of the purpose of the activity, finding a way to acquire the necessary means, without the latter jeopardizing the former. The analysis of those virtues necessary for the agents to pursue the aim of market making relates to the second principle drawn from Aristotelian ethics. We acknowledge that to depict the intentions that move every single agent is particularly challenging. To judge the intention that prompts financial actors to act, requires an in-depth and detailed, case-by-case analysis (see Monge \& Hsieh, 2020 for pay-lending for example), that goes beyond the scope of this paper. Still, even in the absence of such an undertaking, some observations on the nature of their activity can still be made. Before the entrance of the HFT as market makers, and nowadays in the case of the NYSE alone, the specialists - currently known as designated market makers (among which HFT firms are also registered) had an advantageous position that give them preferential access to orders and information in the limit order book, but in return, they had a positive obligation to provide bid and offer quotes. This institutional framework may not have ensured that every market maker acted in accordance with 
the intention of providing continuous liquidity to guarantee a "fair and orderly market" and to ensure that all the benefits that this activity provides are bestowed upon the economy (in other words, the strong interpretation we gave to the intentional promotion of the common good). However, this scheme guaranteed at least an institutional framework designed to promote and protect the good at stake (i.e. a continuous liquidity) and which still complies with our weak interpretation of an intentional promotion of the common good.

The fact that even this system is not perfect and has never been in the past-as demonstrated by the case of the 1987 market crash-should have provided sufficient encouragement to quickly strengthen the existing structure instead of delegating its aim to market forces, which eventually weakened it. In summary: the market-making activity we described had a clear purpose, defined by regulations and norms that directed the intention of the agents who practiced it. In Aristotelian terms, this meant that the market-making activity could be counted as a form of natural chrematistics conceived and designed to contribute to the common good. Virtuous agents intent on achieving the purpose of the market-making activity could thus have embarked on the quest for their eudaimonia.

The entrance of HFT market makers add a difficulty to the analysis, provided from the lack of an institutional context that informs HFT market makers about the goal to be achieved. This element would not prevent-at a theoretical level - that HFT market makers might freely provide liquidity on an ongoing basis. In fact, we also acknowledge that freedom is a necessary condition for virtuous actions (Wyma, 2015). Given this circumstance, however, the aforementioned virtues of market-makers - courage, justice, temperance, prudence-would still be necessary. In the case of HFT however, the analysis of virtues poses a new problem since the strategies are contained and executed by algorithms. The existence of moral agency in the case of artificial intelligence, within which we can include algorithms (Bostrom \& Yudkowsky, 2014), has been denied by some virtue ethics scholars (Sison et al., 2020). Yet, the responsibility of those technicians who design the algorithms in the first place remains valid. It can be emphasized then that there are no human actions - however technically advanced - that can completely evade moral responsibility, and no technical analysis should be devoid of ethical considerations. Moreover, as underlined by West (2012), "the quants [people in charge of designing most of the algorithms behind current financial strategies] should not be left to operate in a relative ethics vacuum". Events driven by financial technology such as the Black Monday in 1987, or the collapse of the hedge fund Long-Term Capital Management, demonstrate that the absence of ethics in quantitative models/strategies cannot in any way be justified. This is primarily due to the fact that the risk models and the exotic derivatives that quants create for customers, are often not easily understood by front-office managers (Wilmott, 2008). In this sense, and in line with those who claim the necessity to restore the role of practical wisdom in business education (Roca 2008), we also argue in favor of an integral education of financial engineers (Roncella \& Roncella, 2019).

The Aristotelian analysis conducted on the evolution of market-making activity-both at a systemic and individual level-highlights how this has been negatively affected by the introduction of HFT. Regarding the systemic level, there has been a significant redress in the purpose of the activity, while at the individual level, even in the absence of a more granular analysis, it is possible to show the overall difficulty in living out the virtues necessary for the pursuit of the goal of market making.

These two points suggest how HFT's activity responds to the category of an unnatural chrematistics, with consequences that we will elaborate on in the conclusions.

\section{Conclusion}

Aristotle's reflections on trade were not particularly positive. Yet, the general view of trading progressively changed over time, highlighting the potentially positive service it provided to society (Melé, 2016, p. 297). Even the most delicate outcome, the profits of the traders, can be justified while these are compatible with the common good and with the principles of morality (Alves \& Moreira, 2013, p. 214). In accordance with this tradition, chrematistics is justified when it is "integrated into a purpose-bound and socially embedded oikonomia. Yet it can also be torn apart from this context and turn into a boundless pursuit of profit" (Dierksmeier \& Pirson, 2009, p. 424; see also Sison \& Ferrero, 2019).

This paper studies the case of market-making transformation due to HFT, to show how the Aristotelian distinction between natural chrematistics, which is aimed at serving the real economy, and unnatural chrematistics, whose ultimate purpose is wealth accumulation, can be a useful criterion to assess the ethical perspective of this activity. In the literature review, we show the dominance of the efficiency argument over that of stability and justice to validate the development of new financial processes and products. Conversely, we endeavored to include, together with the commonly used efficiency argument, a new criterion in the assessment of HFT, but which might also be applied to analyze the market making in general. This approach can be defined as 'purpose oriented' or 'purpose fulfillment'; its main contribution consists of understanding and evaluating the true aim of financial products, processes or strategies with their real performance and activity, to assess their goodness and how they serve the common good of society. 
Regarding the HFT's market making role, we emphasize how, under certain conditions, the activity of market making can be considered as a natural chrematistics because it was designed to serve the purpose of better resource allocation and to offer continuous market liquidity towards the goal of 'fair and orderly markets'. The fact that these goals were not always achieved does not change the institutional purpose/design. In contrast, high-frequency traders supply a market making service by virtue of their speed and willingness to transact with investors, but their end-goal is simply to maximize profits. Therefore, when this activity ceases to be profitable they just stop providing the service and the associated liquidity. As such, HFT market making can only be construed to serve unnatural chrematistics.

Two consequences can be drawn here. The first one concerns the moral character of the agents who perform or embed strategies for high-frequency trading in software that determines the size, nature, and volume of the trades. As noted above, Aristotelian ethics is a virtue ethics, and therefore it discusses chrematistics according to its effects on the human character: the danger of an unnatural chrematistics is to some extent the degeneration of the human being. Interestingly, this threat speaks in particular to rich people's happiness because of the underlying desire for something (i.e. unlimited accumulation) which is irrational, as explained by MacIntyre (2016). The second consequence concerns institutions and specifically, the financial system. As demonstrated by several studies, high-frequency traders aggravate system instability. Moreover, they partake in and reinforce an arms race in which none of its financial players can unilaterally quit. In this sense, what is noteworthy is how personal irrationality, in Aristotelian terms (due to the pursuit of unlimited accumulation), ultimately jeopardizes the achievement of the common good.

What should follow from this? Again, the answer is multifold and can be applied not only to HFT but also to market making in general. First, regulatory institutions should be more aware of all the possible outcomes if they want to foster greater competition, while being more restrictive in order to protect a good such as financial stability. A clear example of this is MiFID II which the EU introduced and is applicable from the 1st of January, 2018, to solve, inter alia, the HFT-related concerns raised by MiFID I. MiFID II brought several new obligations for HFT firms active in the EU equity market and addresses many of the concerns raised in this paper (European Parliament \& Council, 2014, p. \#113). However, these concerns also hold true for the US equity market.

Second, our understanding and assessment of new market makers should be informed not merely by the efficiency argument but first by the consequences that these may have on the moral character of human beings. The latter is an ethical issue that should be undertaken primarily by educational institutions.

Finally, this conclusion shows how the contribution of financial firms to the good of society is not provided automatically by the exclusive pursuit of profits as taught by classic liberalism. On the contrary and expanding their context, firms should reflect on how their activities benefit the society within which they are embedded.

Funding Open access funding provided by Università degli Studi di Siena within the CRUI-CARE Agreement.

\section{Declarations}

Conflict of interest Authors declare that they have no conflict of interests.

Ethical Approval This article does not contain any studies involving human participants or animals performed by either of the authors.

Open Access This article is licensed under a Creative Commons Attribution 4.0 International License, which permits use, sharing, adaptation, distribution and reproduction in any medium or format, as long as you give appropriate credit to the original author(s) and the source, provide a link to the Creative Commons licence, and indicate if changes were made. The images or other third party material in this article are included in the article's Creative Commons licence, unless indicated otherwise in a credit line to the material. If material is not included in the article's Creative Commons licence and your intended use is not permitted by statutory regulation or exceeds the permitted use, you will need to obtain permission directly from the copyright holder. To view a copy of this licence, visit http://creativecommons.org/licenses/by/4.0/.

\section{References}

Abolafia, M. (2001). Making markets: Opportunism and restraint on Wall Street. Harvard University Press.

Anscombe, G. E. M. (1958). Modern moral philosophy. Philosophy, $33(124), 1-19$

Alves, A. A., \& Moreira, J. M. (2013). Business ethics in the School of Salamanca. In C. Lüetge (Ed.), Handbook of the philosophical foundations of business ethics (pp. 207-225). Springer.

Anderson, N., Webber, L., Noss, J., Beal, D., \& Crowley-Reidy, L. (2015). The resilience of financial market liquidity. Financial Stability Paper N. 34. Bank of England.

Angel, J. J., \& McCabe, D. (2013). Fairness in financial markets: The case of high frequency trading. Journal of Business Ethics, $112(4), 585-595$.

Angel, J. J., Harris, L. E., \& Spatt, C. S. (2011). Equity trading in the 21 st century. The Quarterly Journal of Finance, 1(01), 1-53.

Aristotle. (1985). Nicomachean ethics (trans: Irwin, T.). Hackett Publishing.

Aristotle. (1990). In S. Everson (Ed.), The politics. Cambridge University Press.

Arnuk, S., \& Saluzzi, J. (2012). Broken markets: How high frequency trading and predatory practices on Wall Street are destroying investor confidence and your portfolio. FT Press.

Biais, B., Declerck, F., \& Moinas, S. (2016). Who supplies liquidity, how and when? BIS Working Papers N. 563. Retrieved January 
22, 2019, from https://papers.ssrn.com/sol3/papers.cfm?abstract_ $\mathrm{id}=2789736$.

Blocher, J., Cooper, R., Seddon, J., \& Van Vliet, B. (2016). Phantom liquidity and high-frequency quoting. The Journal of Trading, $11(3), 6-15$.

Boatright, J. R. (2013). Ethics in finance. Wiley.

Bostrom, N., \& Yudkowsky, E. (2014). The ethics of artificial intelligence. In The Cambridge handbook of artificial intelligence (Vol. 1, pp. 316-334). Cambridge University Press.

Brogaard, J., Hendershott, T., \& Riordan, R. (2014). High-frequency trading and price discovery. The Review of Financial Studies, 27(8), 2267-2306.

Busch, D. (2016). MiFID II: Regulating high-frequency trading, other forms of algorithmic trading and direct electronic market access. Law and Financial Markets Review, 10(2), 72-82.

Carrion, A. (2013). Very fast money: High-frequency trading on the NASDAQ. Journal of Financial Markets, 16(4), 680-711.

CFTC-SEC. (2010a). Preliminary findings in review of May 6 market events. Retrieved May 30, 2018, from https://www.sec.gov/news/ press/2010/2010-81.htm.

CFTC-SEC. (2010b). Findings regarding the market events of May 6 , 2010. Retrieved March 10, 2018, from https://www.sec.gov/news/ studies/2010/marketevents-report.pdf.

Cooper, R., Davis, M., \& Van Vliet, B. (2016). The mysterious ethics of high-frequency trading. Business Ethics Quarterly, 26(1), 1-22.

Cooper, R., Davis, M., Kumiega, A., \& Van Vliet, B. (2020). Ethics for automated financial markets. In Handbook on ethics in finance (pp. 1-18). Springer.

Crespo, R. F. (2013). A re-assessment of Aristotle's economic thought (Vol. 159). Routledge.

Deutsche Bundesbank. (2016). Significance and impact of high-frequency trading in the German capital market. Monthly Report 37. Retrieved January 28, 2018, from https://www.bundesbank. de/Redaktion/EN/Downloads/Publications/Monthly_Report_ Articles/2016/2016_10_high-frequency_trading.pdf?_blob= publicationFile.

Dierksmeier, C., \& Pirson, M. (2009). Oikonomia versus chrematistike: Learning from Aristotle about the future orientation of business management. Journal of Business Ethics, 88(3), 417-430.

Edmans, A. (2020). Grow the pie: How great companies deliver both purpose and profit. Cambridge University Press.

Elliott, D. J. (2015). Market liquidity: A primer. In Economic studies. The Brookings Institution.

European Parliament and Council. (2014). Directive 2014/65/EU. Office Journal of the European Union. https://eur-lex.europa.eu/ legal-content/EN/TXT/PDF/?uri=CELEX:32014L0065\&from= IT.

Ferrero, I., \& Sison, A. J. G. (2014). A quantitative analysis of authors, schools and themes in virtue ethics articles in business ethics and management journals (1980-2011). Business Ethics: A European Review, 23(4), 375-400.

Ferrero, I., \& Sison, A. J. G. (2017). Aristotle and MacIntyre on the virtues in finance. In A. J. G. Sison, G. Beabout, \& I. Ferrero (Eds.), Handbook of virtue ethics in business and management (pp. 1153-1161). Springer

Ferrero, I., Roncella, A., \& Rocchi, M. (2020). A virtue ethics approach in finance. In Handbook on ethics in finance (pp. 1-20). Springer. https://doi.org/10.1007/978-3-030-00001-1_25-1.

Gerig, A. (2015). High-frequency trading synchronizes prices in financial markets. Available at SSRN: https://ssrn.com/abstract=21732 47.

Haldane, A. G. (2012). The race to zero. In The global macro economy and finance (pp. 245-270). Palgrave Macmillan.

Hartman, E. (1996). Organizational ethics and the good life. Oxford University Press.
Hendershott, T., Jones, C. M., \& Menkveld, A. J. (2011). Does algorithmic trading improve liquidity? The Journal of Finance, 66(1), $1-33$.

Hsieh, N., Meyer, M., Rodin, D., \& Van`t Klooster, J. E. N. S. . (2018). The social purpose of corporations. Journal of the British Academy, 6(s1), 49-73.

International Monetary Fund. (2015). Global Financial Stability Report, October.

Jain, P. K., Jain, P., \& McInish, T. (2016). Does high-frequency trading increase systemic risk? Journal of Financial Markets, 31, 1-24.

Kirilenko, A., Kyle, A. S., Samadi, M., \& Tuzun, T. (2017). The Flash Crash: High-frequency trading in an electronic market. The Journal of Finance, 72(3), 967-998.

Koehn, D., \& Koehn, J. L. (2014). Ethical issues with dark liquidity and the ethics of possible remedies. Seven Pillars Institute. Retrieved May 28, 2018, from https://sevenpillarsinstitute.org/ wp-content/uploads/2017/11/Dark-Liquidity-EDITED.pdf.

Lewis, M. (2014). Flash boys. WW Norton.

Marti, E., \& Scherer, A. G. (2016). Financial regulation and social welfare: The critical contribution of management theory. Academy of Management Review, 41(2), 298-323.

Marx, K. (2004). Capital: (Vol. I). Penguin.

MacIntyre, A. (1984). After virtue: A study in moral theory. University of Notre Dame Press.

MacIntyre, A. (2016). Ethics in the conflicts of modernity: An essay on desire, practical reasoning, and narrative. Cambridge University Press.

McCloskey, D. N. (2010). The Bourgeois virtues: Ethics for an age of commerce. University of Chicago Press.

McNamara, S. (2016). The law and ethics of high-frequency trading. Minnesota Journal of Law Science and Technology, 17, 71.

Meikle, S. (1995). Aristotle's economic thought. Clarendon Press.

Melé, D. (2016). Re-thinking capitalism: What we can learn from Scholasticism? Journal of Business Ethics, 133(2), 293-304.

Melé, D. (2019). Business ethics in action: Seeking human excellence in organizations ( $2^{\text {nd }}$ ed.). Palgrave Macmillan.

Menkveld, A. J. (2013). High frequency trading and the new market makers. Journal of Financial Markets, 16(4), 712-740.

Miller, S. (2017). Financial markets and institutional purposes: The normative issues. In L. Herzog (Ed.), Just financial markets? Finance in a just society. Oxford University Press.

Monge, R., \& Hsieh, N. H. (2020). Recovering the logic of Double Effect for business: Intentions, proportionality, and impermissible harms. Business Ethics Quarterly, 30(3), 361-387.

Moore, G. (2008). Re-imagining the morality of management: A modern virtue ethics approach. Business Ethics Quarterly, 18(4), 483-511.

Moore, G., \& Beadle, R. (2006). In search of organizational virtue in business: Agents, goods, practices, institutions and environments. Organization Studies, 27(3), 369-389.

Plato. (2007). The Republic. Penguin Classics.

O'Hara, M. (1998). Market microstructure theory. Wiley.

O'Hara, M. (2015). High frequency market microstructure. Journal of Financial Economics, 116(2), 257-270.

O'Hara, M. (2016). Something for nothing: Arbitrage and ethics on Wall Street. WW Norton and Company.

O'Hara, M., \& Oldfield, G. S. (1986). The microeconomics of market making. The Journal of Financial and Quantitative Analysis, 21(4), 361-376.

Rogow, G. (2012). Collocation: The root of all high-frequency evil? The Wall Street Journal. Retrieved May 30, 2018, from https:// blogs.wsj.com/marketbeat/2012/09/20/collocation-the-root-of-allhigh-frequency-trading-evil/.

Roncella, A., \& Roncella, L. (2019). Finance needs 'Bilinguals' too. Finance and Bien Commun/common Good, 46 and 47, 61-72. 
Sandel, M. J. (2012). What money can't buy: The moral limits of markets. Macmillan.

Sandel, M. J. (2013). Market reasoning as moral reasoning: Why economists should re-engage with political philosophy. Journal of Economic Perspectives, 27(4), 121-140.

Schlag, M. (2017). The business Francis means: Understanding the Pope's message on the economy. Catholic University of America Press.

SEC. (2010). Concept release on equity market structure. Retrieved May 29, from https://www.sec.gov/rules/concept/2010/34-61358. pdf.

Shiller, R. J. (2013). Finance and the good society. Princeton University Press.

Sison, A. J. G. (2003). The moral capital of leaders: Why virtue matters. Edward Elgar Publishing.

Sison, A. J. G., Beabout, G., \& Ferrero, I. (2017). Handbook of virtue ethics in business and management. Springer.

Sison, A. J. G., \& Ferrero, I. (2019). Is financialization a vice? Perspectives from virtue ethics and catholic social teaching. In C. Cowton, J. Dempsey \& T. Sorell (Eds.), Business ethics after the financial crisis: Lessons from the crash. Routledge.

Sison, A. J. G., Ferrero, I., \& Redìn, D. (2020). How virtue ethics can engage with AI in business. Working paper. Universidad de Navarra.
Solomon, R. C. (1992). Ethics and excellence. Oxford University Press. Stiglitz, J. E. (2014). Tapping the brakes: Are less active markets safer and better for the economy? In Federal Reserve Bank of Atlanta 2014 financial markets conference tuning financial regulation for stability and efficiency, April (Vol. 15).

Thaler, R. H., \& Sunstein, C. R. (2003). Libertarian paternalism. American Economic Review, 93(2), 175-179.

Tirole, J. (2017). Economics for the common good. Princeton University Press.

Yadav, Y. (2016). Insider trading and market structure. UCLA Law Review, 63, 968.

West, J. M. (2012). Money mathematics: Examining ethics education in quantitative finance. Journal of Business Ethics Education, 9(Special Issue), 25-39.

Wilmott, P. (2008). This is no longer funny. Retrieved December 2020, from https://wilmott.com/this-is-no-longer-funny/.

Wyma, K. D. (2015). The case for investment advising as a virtuebased practice. Journal of Business Ethics, 127(1), 231-249.

Zingales, L. (2015). Presidential address: Does finance benefit society? The Journal of Finance, 70(4), 1327-1363.

Publisher's Note Springer Nature remains neutral with regard to jurisdictional claims in published maps and institutional affiliations. 